\title{
SYSTEMATIC REVIEW OF VALUE ENGINEERING RESEARCH STUDIES IN INDONESIA
}

\author{
Perdana Miraj $^{1 *}$, Ahmad Dofir ${ }^{1}$, Azaria Andreas ${ }^{1}$, Mohammed Ali Berawi ${ }^{2}$, Saipol Bari Bin \\ Abd Karim ${ }^{3}$ \\ ${ }^{1}$ Department of Civil Engineering, Faculty of Engineering, Pancasila University, Srengseng Sawah \\ Jakarta Selatan 12640, Indonesia \\ ${ }^{2}$ Department of Civil Engineering, Faculty of Engineering, Universitas Indonesia, Kampus Baru UI \\ Depok 16424, Indonesia \\ ${ }^{3}$ Department of Quantity Surveying. Faculty of Built Environment, University of Malaya, Malaysia
}

(Received: December 2019 / Revised: December 2019 / Accepted: December 2019)

\begin{abstract}
Value engineering (VE) plays a significant role in improving project competitiveness and propose an alternative solution to create added value for a project. Despite well-adopted in various countries worldwide, VE development shows stagnant progress in Indonesia. This can be seen by number of project and publications involving VE in Indonesia. In fact, academics and researchers argued the concept will highly contribute to advocate the benefits of VE into the public and private project practice. The research aims to investigate publications affiliated with Indonesian institutions and recommend strategies for VE implementation in the country. This paper uses a systematic review by taking into account the database library for extraction. The result shows that academics and researcher from Indonesian institutions regularly publish their work in VE study. However, the number of publication in refereed journals is much less compared papers in proceedings. The findings suggest some strategies to increase the publication and how to be involved in project development in Indonesia.
\end{abstract}

Keywords: Indonesia; Review; Value engineering; VOSviewer

\section{INTRODUCTION}

Value engineering (VE) has become an alternative approach to assist decision making by taking into account the degree of value. Academics and researchers articulated VE in various ways and VE definition is far into an agreement. However, it is believed that VE is a means of decision making by considering systematic and structured ways that involved multi-discipline background in the process. Many sectors have been adopting this concept and gained benefits from the VE process including construction (Ojo \& Ogunsemi, 2019; Zimina, Ballard, \& Pasquire, 2012), waste (Chidambaram, 2018), energy (Shu, Duanmu, Zhang, \& Zhu, 2010), automation (Marzouk, 2011), infrastructure (M.-J. Lee, Lim, \& Hunter, 2010), manufacturing (Ibusuki \& Kaminski, 2007; Sreenivasan, Goel, \& Bourell, 2010), and not limited to information technology (Tohidi, 2011). VE not only offers cost efficiency for the project output but also improves project performance, provides better communication, and generates higher value.

*Corresponding author's email: perdanamiraj@univpancasila.ac.id 
VE adopted in facility management optimizes corporate cost and risk by taking into account a modified formula of VE process. The results show value improvement which produce alternative option for decision maker (Zhao, 2019). A water transmission system in Iran obtained benefits from VE adoption by $41 \%$ savings from construction cost and environmental improvement (Shahhosseini, Afshar, \& Amiri, 2018). On the other hand, VE has been involved in decision-making process to select façade materials which potentially minimize defects at the design stage (J.-S. Lee, 2018). Researchers also attempt to evaluate a combination of digitalization and VE through building information modeling (BIM) and VE idea bank. The study is argued to contribute to the VE study improvement in the future (Park, Kim, Park, Goh, \& Pedro, 2017). VE implementation also investigated by a researcher in term of legal aspect and Indonesia regulation, but the results require further elaboration to incorporate VE extensively in project development in Indonesia (Yanita \& Mochtar, 2018).

VE has also been adopted in many countries to improve values of the project including Indonesia. However, unlike neighboring countries such as Malaysia, Singapore or Thailand which establish a mutual relationship within the domestic association, industries, and academics, Indonesian value engineers remain unknown for their works. This condition also can be seen by limited regulations that support value engineering to be involved in public project development. In developed countries such as the United States, highway projects higher than US\$ 50 billion and bridge projects more than US\$ 40 billion have to conduct VE analysis for project delivery (Federal Highway Administration, 2019). The private sector also tends to hesitate using VE practitioners due to several reasons including cost efficiency, experiences, and limited benefits to generate revenue.

Academics play a significant role in transferring knowledge about VE into practice. Although the dissemination and adoption require collaboration among stakeholders, theory, and state of the art from lecturers are argued to have a huge impact to advocate VE concept into public and private project development. The research aims to map publications affiliated to Indonesian institutions based on library database containing abstracts and citations of academic journal articles. This paper illustrates the current condition of publication from Indonesian institution and recommends strategies for VE implementation in Indonesia.

\section{METHODOLOGY}

This paper adopts two stages of approach to evaluate the manuscript published in journals and proceedings published in Scopus. Firstly, some keywords and exclusions are conducted to reach research objectives (Mohd Ali Berawi, Ibrahim, ., \& Miraj, 2019; Rahman et al., 2018). Keywords should be either value engineering or value management but not earned value management. The last keyword is quite different from the methodology, philosophy, and tools compared to the rest of the two (Mohammed Ali Berawi, Miraj, Windrayani, \& Berawi, 2019; Mohammed Ali Berawi, Susantono, Miraj, \& Nurmadinah, 2018). This paper select articles based on the title and abstract published during the past decade. The document should be either in the journal of proceedings and the authors should be affiliated with Indonesian institution. The search string is described as follows.

TITLE-ABS ( ( "value engineering" OR "value management" ) AND NOT ( "earned value management" ) ) AND DOCTYPE ( ar OR cp ) AND PUBYEAR > 2008 AND PUBYEAR < 2020 AND ( LIMIT-TO ( AFFILCOUNTRY, "Indonesia" ) )

In the second stage, a bibliometric analysis by using VosViewer was used to map and illustrate the findings. This tool is argued as one powerful tool to generate mapping and visualize them for analysis (Van Eck \& Waltman, 2009). The result proposes authors who regularly publish 
their work related to value engineering and value management as well as the topic being investigated by the Indonesian researchers during the past decade.

\section{RESULTS}

\subsection{The result from Scopus Database}

In the first stage, 38 papers are proposed matching selected keywords. Compared to other countries, the total publication from Indonesia are relatively higher than neighbouring countries such as Singapore, Thailand, or the Philippines but lower than Malaysia which has a total by 48 publications during the past decade.

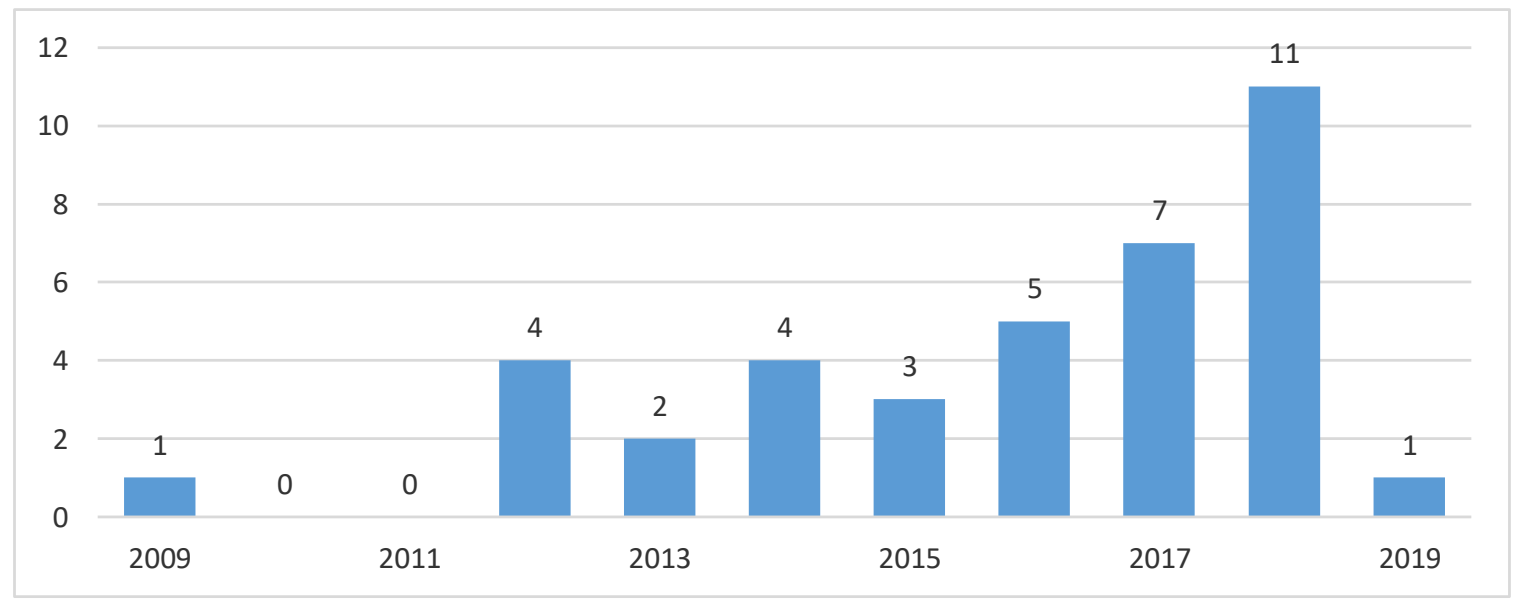

Figure 1. Annual Publication Based on Scopus

The number of researchers published in this topic from Indonesia is increasing during the past decade. Initially, there is only one paper published in 2009. Although none publishing for value engineering in 2010 and 2011, the number drastically climbs into a minimum of two papers each year to 2018. This year, the number of paper published is one. The detail publication can be seen in Figure 1.

The result also shows affiliation from the home-based of each researcher. Academics from Universitas Indonesia highly contribute related to value engineering studies by 13 publications, followed by Bandung Institute of Technology with 8 publications and three institutions (University of Malaya, Universitas Pancasila, and Bung Hatta University) with 4 publications. From this result, some researchers also collaborate with the institution from Malaysia particularly from the University of Malaya. The detail can be seen in Figure 2.

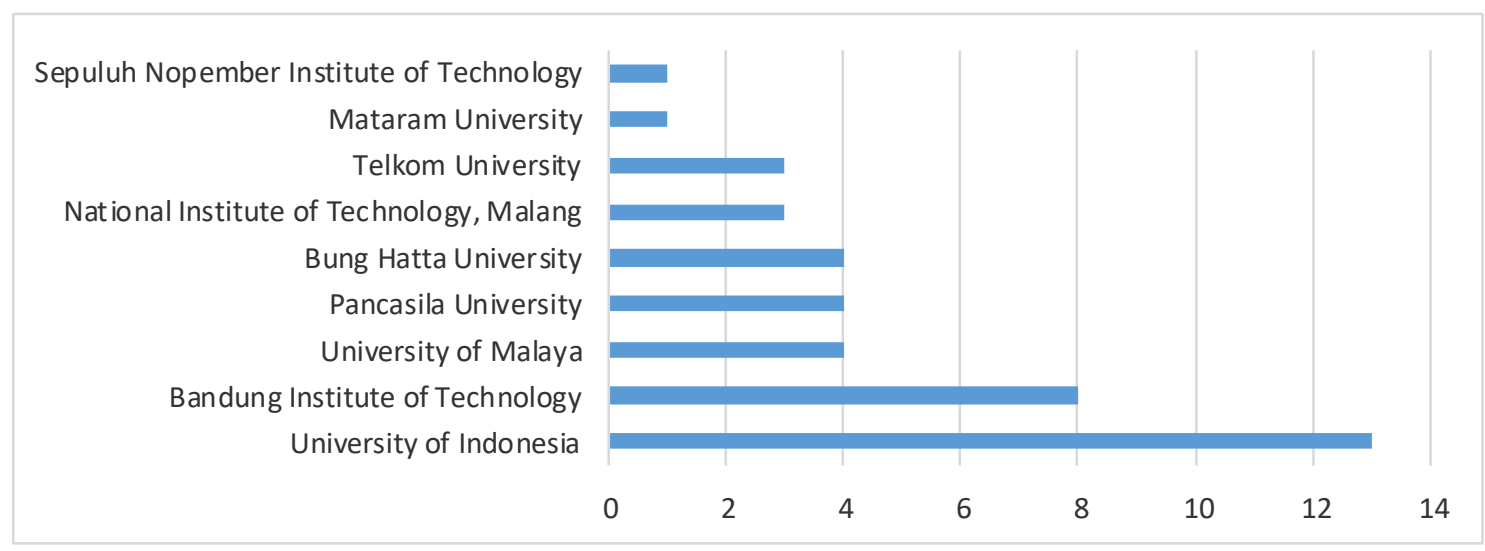

Figure 2. Publication Based on Institutions 


\subsection{Bibliographic Analysis}

VosViewer was used to evaluate the influential studies of value engineering in Indonesia. Cooccurrence was adopted by taking into account keywords as the unit of analysis and fractional as the counting method. Minimum number of occurrences of a keyword was set into two. A total of 49 documents was suggested by the software and argued connected. The analysis can be seen in Figure 3.

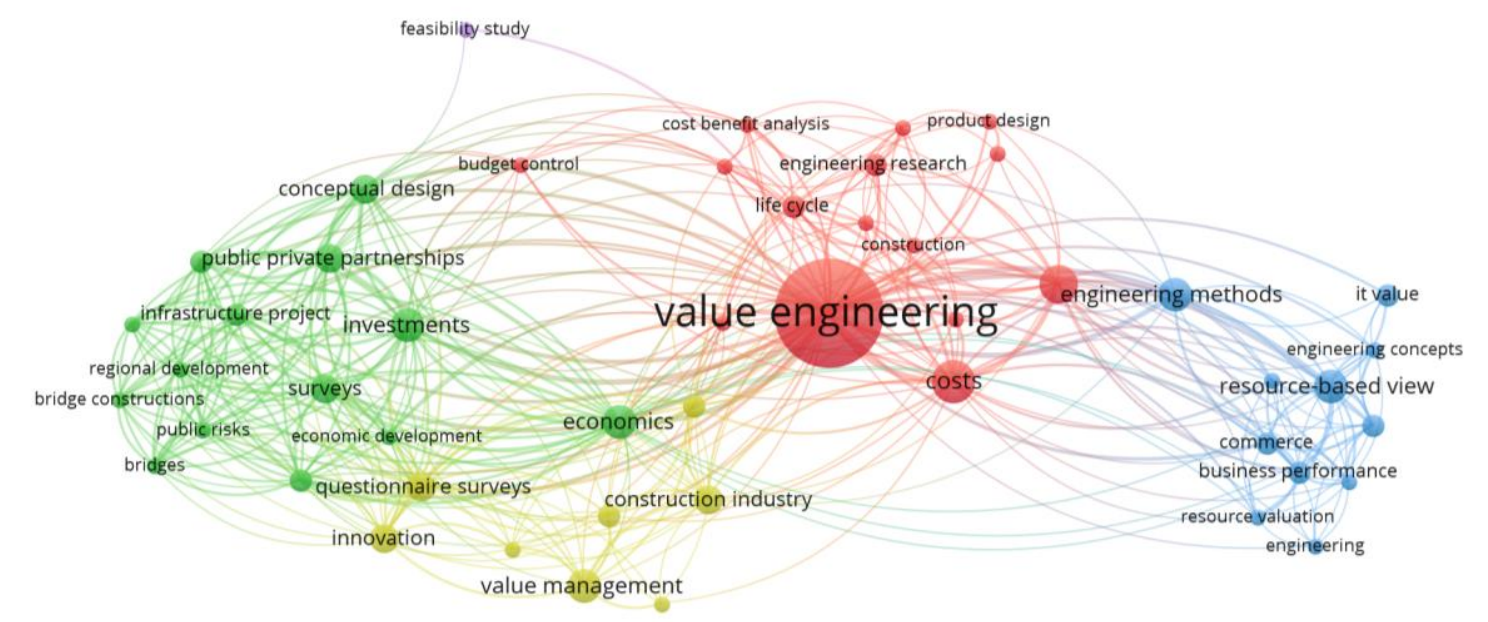

\section{\& ${ }^{\circ}$ VOSviewer}

Figure 3. Publication Mapping in the Topic of Value Engineering Based on Scopus

From the previous visualization, the software illustrates network based on line and size of circle. The largest circle and bold curve line indicate the highest topic in the case study. The figure shows the researcher elaborate value engineering as the sole topic of interest and has low connection to other topic such as feasibility study. Limited correlation also found from the investigated researcher that they mostly take into account cost, engineering methods and life cycle which are shown in similar circle color. A growing interest has started to increase in the left side with green color from the topic of value engineering related to a public-private partnership, public risks, investment, and other associated components.

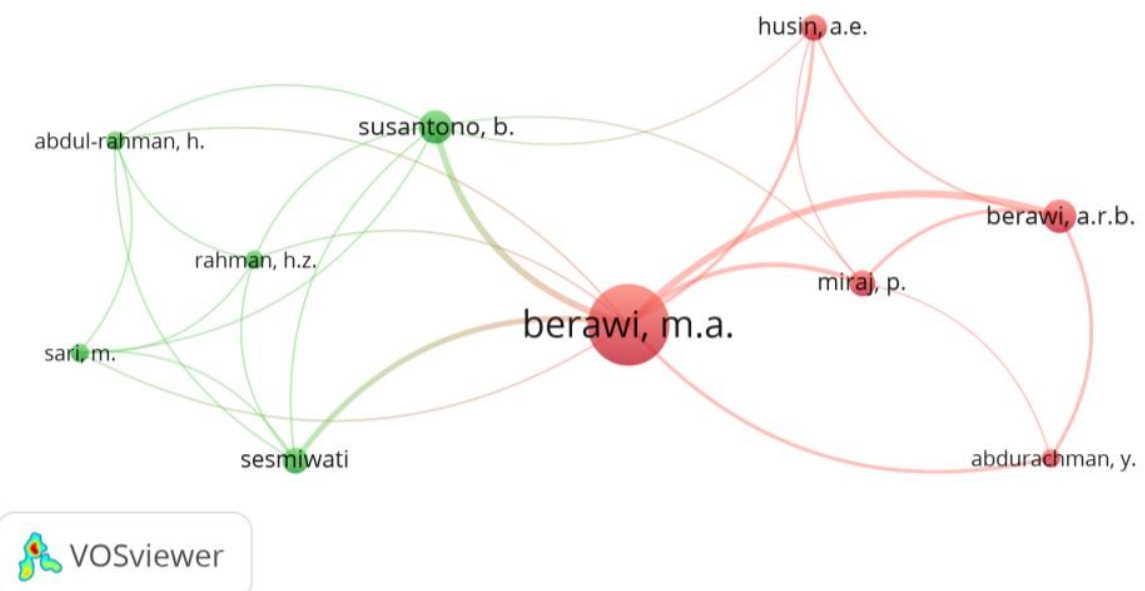

Figure 4. Academics Publishing Works related to Value Engineering in Indonesia 
VosViewer also maps author correlation through co-authorship. This paper uses author as the unit of analysis and fractional as the counting method. Minimum number of occurrences of a keyword was set into two. A total of 16 documents was proposed by the software and only ten of them are connected. The size of the circle and line depth shows the impact of academics in value engineering. Berawi, M.A becomes the central role in value engineering and is highly connected with Berawi, A.R.B, and Susantono, B. Other researchers also publish their paper and connected as shown in Figure 4.

Based on the previous result, the number of publications from Indonesian academics and researchers is competitive. Nevertheless, the papers published in the journals remain limited compared to proceedings. This condition may be related to minimum involvement from association, industries and the government. The government may initiate a project that surpasses a particular threshold to adopt VE for a case study. This will challenge the VE team to prove their capability to propose higher value compared to the previous one. Most of the project conducted by researcher tend to categorize as conceptual design rather than a practical one. The private sector may contribute to the increase of VE adoption through design competition or a small project as the sampling for implementation. Furthermore, VE association in Indonesia is relatively stagnant and limited discussion is conducted to share knowledge and experience among national VE practitioners even with international experts. It is suggested that a focus group discussion and seminars are regularly held to expand VE learning and cope with contextual challenges. Certification and education should be performed to promote VE practitioners not only in the domestic but also in international market.

\section{CONCLUSION}

Value engineering has been adopted across countries and gained significant improvement in term of project competitiveness. Although proposing benefits in the longer term, VE application in Indonesia remains limited. Academics through dissemination and socialization play a significant role in expanding VE knowledge and adoption. This research attempts to map publications from Indonesian institutions by taking into account the international library database. The result shows that the publications are relatively high, but most of them were published in proceedings instead of refereed journals. This paper suggests several strategies to increase publications and adoption in project practice including the collaboration among academics, association, industry, and government.

Despite the findings from this research, some limitations are found. Firstly, this paper only considers Scopus as the international library database. There are numbers of other databases which can be used to extract references such as Google Scholar and Web of Science. The combination from this library may improve the accuracy of this paper. Secondly, this paper only counts Indonesia as the case study of VE adoption. A comparison from neighbouring countries such as Malaysia, Singapore, Thailand, Vietnam, and others are suggested to generate a comprehensive result. Last, the analysis only uses VosViewer for illustration and presentation of findings. It is suggested that future work will adopt a combination of other available analysis.

\section{ACKNOWLEDGEMENT}

This research is supported by a grant from Faculty of Engineering, Pancasila University 2019.

\section{REFERENCES}

Berawi, M. A., Ibrahim, B. E., ., G., \& Miraj, P. (2019). Developing A Conceptual Design of Transit-Oriented Development To Improve Urban Land Use Planning. Journal of Design 
and Built Environment(1), 40-48\%V 19. Retrieved from https://ejournal.um.edu.my/index.php/jdbe/article/view/17775.

Berawi, M. A., Miraj, P., Windrayani, R., \& Berawi, A. R. B. (2019). Stakeholders' perspectives on green building rating: A case study in Indonesia. Heliyon, 5(3), e01328.

Berawi, M. A., Susantono, B., Miraj, P., \& Nurmadinah, F. (2018). Prioritizing airport development plan to optimize financial feasibility. Aviation, 22(3), 115-128.

Chidambaram, S. (2018). Application of building information modelling for reinforcement waste minimisation. Paper presented at the Proceedings of the Institution of Civil Engineers-Waste and Resource Management.

Federal Highway Administration. (2019). Value engineering final rule. Retrieved from https://www.fhwa.dot.gov/ve/

Ibusuki, U., \& Kaminski, P. C. (2007). Product development process with focus on value engineering and target-costing: A case study in an automotive company. International Journal of Production Economics, 105(2), 459-474.

Lee, J.-S. (2018). Value engineering for defect prevention on building façade. Journal of Construction Engineering and Management, 144(8), 04018069.

Lee, M.-J., Lim, J.-K., \& Hunter, G. (2010). Performance-based value engineering application to public highway construction. KSCE Journal of Civil Engineering, 14(3), 261-271.

Marzouk, M. (2011). ELECTRE III model for value engineering applications. Automation in Construction, 20(5), 596-600.

Ojo, L. D., \& Ogunsemi, D. R. (2019). Critical drivers (CDs) of value management adoption in the Nigerian construction industry: A Delphi study. Journal of Engineering, Design and Technology, 17(1), 250-264.

Park, C.-S., Kim, H.-J., Park, H.-T., Goh, J.-H., \& Pedro, A. (2017). BIM-based idea bank for managing value engineering ideas. International Journal of Project Management, 35(4), 699-713.

Rahman, H. Z., Berawi, M. A., Susantono, B., Miraj, P., Petroceany, J. S., \& Maya, R. (2018). Investigation of an operation and maintenance framework in the railway industry: a case study of the makassar-parepare. International Journal of Technology, 9(3), 549-557.

Shahhosseini, V., Afshar, M. R., \& Amiri, O. (2018). Value engineering practices in infrastructure projects: a case study of Ilam Gas Refinery's water transmission system at Reno Mountain, Iran. International Journal of Construction Management, 18(5), 351-363.

Shu, H., Duanmu, L., Zhang, C., \& Zhu, Y. (2010). Study on the decision-making of district cooling and heating systems by means of value engineering. Renewable Energy, 35(9), 1929-1939.

Sreenivasan, R., Goel, A., \& Bourell, D. L. (2010). Sustainability issues in laser-based additive manufacturing. Physics Procedia, 5, 81-90.

Tohidi, H. (2011). Review the benefits of using value engineering in information technology project management. Procedia Computer Science, 3, 917-924.

Van Eck, N., \& Waltman, L. (2009). Software survey: VOSviewer, a computer program for bibliometric mapping. Scientometrics, 84(2), 523-538.

Yanita, R., \& Mochtar, K. (2018). Legal aspect of value engineering implementation in Jakarta (Indonesia) construction projects. International Journal of Construction Management, 1-9.

Zhao, C. (2019). Facility decision making process with modified value engineering approach. Journal of Corporate Real Estate, 21(2), 112-129. doi:10.1108/JCRE-01-2018-0002

Zimina, D., Ballard, G., \& Pasquire, C. (2012). Target value design: using collaboration and a lean approach to reduce construction cost. Construction Management and Economics, 30(5), 383-398. 